Article

\title{
The Role of Common-Pool Resources' Institutional Robustness in a Collective Action Dilemma under Environmental Variations
}

\author{
Ana Alicia Dipierri ${ }^{1, *}$ (D) and Dimitrios Zikos ${ }^{2}$ \\ 1 Fonds de la Recherche Scientifique (FNRS Aspirant research fellow), Rue d'Egmont 5, B-1000 Brussels, \\ Belgium \& Centre Emile Bernheim de Recherche Interdisciplinaire en Gestion (CEBRIG), \\ Solvay Brussels School of Economics and Management, Université libre de Bruxelles (ULB), Avenue F.D. \\ Roosevelt 50 CP 139, B-1050 Brussels, Belgium \\ 2 International Development and Economics Programme, Department of Economics, \\ HTW University of Applied Sciences, Treskowallee 8, 10318 Berlin, Germany; Dimitrios.Zikos@htw-berlin.de \\ * Correspondence: Alicia.Dipierri@ulb.be
}

Received: 12 September 2020; Accepted: 4 December 2020; Published: 16 December 2020

\begin{abstract}
Extreme environmental variations, as a phenomenon deriving from climate change, led to an exacerbated uncertainty on water availability and increased the likelihood of conflicts regarding water-dependent activities such as agriculture. In this paper, we investigate the role of conflict resolution mechanisms-one of Ostrom's acclaimed Design Principles-when social-ecological systems are exposed to physical external disturbances. The theoretical propositions predict that social-ecological systems with conflict-resolution mechanisms will perform better than those without them. We tested this proposition through a framed field experiment that mimicked an irrigation system. This asymmetric setting exposed farmers to two (2) dilemmas: (i) how much to invest in the communal irrigation system's maintenance and (ii) how much water to extract. The setting added a layer of complexity: water availability depended not only on the investment but also on the environmental variability. Our findings confirmed the theoretical proposition: groups with stronger 'institutional robustness' can cope with environmental variations better than those with weaker robustness. However, we also found that some groups, despite lacking conflict-resolution mechanisms, were also able to address environmental variations. We explored potential explanatory variables to these unexpected results. We found that subjects' and groups' attributes might address uncertainty and avert conflict. Thus, social-ecological systems' capacity to respond to external disturbances, such as environmental variations, might not only be a question of Design Principles. Instead, it might also be strongly related to group members' attributes and group dynamics. Our results pave the way for further research, hinting that some groups might be better equipped for mitigation measures, while others might be better equipped for adaptation measures.
\end{abstract}

Keywords: irrigation systems; common-pool resource governance; environmental variability; collective action; institutional robustness; climate change

\section{Introduction}

Climate change makes extreme weather phenomena the 'new normal'. It introduces several layers of uncertainties affecting the way humans relate to nature. The seminal paper of this special issue: "Revisiting the Role of Institutions in Transformative Contexts: Institutional Change and Conflicts" [1], brings to the discussion this unprecedented setting for humanity and the potential surge of conflicts with a focus on the role of institutional change. The author argues three (3) causes for institutional change: (i) the lack of an institution, (ii) a futile institution, or (iii) the need to adjust the institution 
given external disturbances (p. 9, [1]). This paper dives into the latter cause for institutional change, where climate change introduces the external disturbances. More precisely, we investigate the link between common-pool resources (CPR) and conflicts when the social-ecological system (SES) framing the CPR is affected by an external disturbance.

CPRs are fertile ground for 'conflict' considering the conceptualization adopted by Zikos where conflicts are understood as "an important contextual factor under which institutional processes take place and as a framing condition for the (non)cooperative strategies adopted by involved actors, ultimately influencing the success of introduced institutional changes" (p. 4, [1]). Conflicts are the setting where actors have incompatible natural resource governance objectives [2]. In CPRs, the incompatibility can be: (i) between the users' 'individual short-term objectives' (to under-invest, over-extract) or (ii) between their short-term objectives and the 'social long-term objective' (to over-invest and under extract).

It is well documented that uncertainty might foster these incompatibilities leading to competition and potential conflict scenarios [3-5]. Then, the typical CPR's social dilemmas, under extreme environmental variability, might be heightened. In the 'new normal', it is not only a question of how much to extract from the CPR, nor how much to invest for its maintenance. It is also that the payoff of these decisions becomes increasingly uncertain. Thus, the final payoffs do not depend only on the decision-making processes alone. Unpredictable climatic phenomena with unknown effects also determine them.

In particular, we focused on communal irrigation systems governance under environmental variability, because water, like CPR, is one of the most negatively affected natural resources [6] in this unprecedented setting for humanity [7]. Climate change affects irrigation water in general, and agricultural productivity in particular, through different channels: (i) the increased temperature fosters evaporation, hence, more water is needed to obtain the same productivity, (ii) the greater interannual precipitations variability leads to droughts and floods directly affecting, already stressed, water-dependent activities like agriculture [8], and (iii) extreme events destroyed yields and productions systems increasing return on investment risks. Thus, the climatic emergency requires not only an "efficient water distribution and allocation institutions" (p. 731, [9]) but also a better understanding of how users are collectively actioning in this 'new normal'. Adano et al. [3] found that the outcomes vary between natural resources scarcity and abundance scenarios in the drylands of Kenya. While during scarcity, users cooperate, the opposite occurs during abundance, particularly in combination with poor governance. These results are interesting because water-an ambivalent common-pool resource (CPR) - contains both conflict and cooperation-inducing qualities [10-14] and is emerging as an emblematic resource. However, research has shown that the vulnerability to water variability varies substantially across sectors having time and space as relevant variables affecting it [15]. Indeed, the problem of uncertainties regarding water availability becomes particularly acute to small farmers across the globe as they generally lack the resources to cope with them. Contrary to large-scale industrialized agriculture, small farmers cannot rely on costly investments on water storage, drilling, or technological innovation to mitigate the effects of climate change [6]. Thus, in this paper, we use water as the lens to study how small-scale farmers react, not to scarcity or abundance, but to uncertain water availability scenarios created by climate change from an institutionalist perspective.

It could be argued that climate change causes not only negative externalities but also positive externalities and that the final impact of climate change is timely and spatially determined $[3,9,15]$. These polarized outcomes are acute in the agricultural sector, an emblematic environmentally dependent economic sector. Argentina, a typical agricultural country, is a clear example of these multifaceted climate change impacts. While environmental variability has increased yields production in the central area of Argentina through a wetting process, it has also implied reduced productivity in the northerner areas due to increased temperatures and interannual precipitation variability that resulted in droughts and floods [16,17]. Thus, we conducted a case study in the latter region: the Northwest.

In particular, our research focuses on the Design Principles (DPs) that are necessary to enable resource users to transform the rules and reach desirable collective outcomes $[5,18,19]$. In this sense, it is 
well documented that: (i) small farming communities [20], (ii) with institutional arrangements [3,18] (iii), a certain level of trust [21], (iv), and social capital [22] can cope with uncertainties and resolve external disturbances to their system to a larger extent than communities lacking such qualities [23]. By extension, we could intuitively expect that the existence of conflict-resolution-mechanisms-one of the DPs proposed by Ostrom [24] —will enable groups to cope better with the conflicts emerging from uncertainties and act collectively to overcome the social dilemma. However, empirical studies on CPRs focusing on the impact of uncertainty on conflicts over resources in such a frame remain surprisingly underexplored [25] with some exceptions e.g., [26-29]. Clear evidence of the need for more research regarding uncertainty effects on common-pool resources governance is the systematic review conducted by Mantilla [30]. In the time frame between 1990 and 2014, the author only found 33 papers working on this link. Additionally, the sources of uncertainty and the methodology differ between the papers.

Thus, the working hypothesis is that groups with a higher level of 'institutional robustness', reporting the existence of conflict-resolution mechanisms, will cope better with environmental variability (EV) than the others. In this frame, we empirically explored the theoretical propositions through our case study with a multi-method approach encompassing a framed-field experiment, a survey conducted with all the subjects participating in the sessions to assess relevant qualitative characteristics that may not be sufficiently captured by the framed-field experiment (socio-demographic variables, physical settings of the communities, and experience with irrigation systems management), and semi structured interviews with key informants.

Overall, in our paper, the actors are the small-scale farmers, and as explained earlier, conflict comes hand in hand with the CPRs dilemmas exacerbated by an additional layer of complexity: water uncertainty. In this context, conflict might influence not only the success but also the potential failure of the solutions given to the Social-Ecological Systems' (SESs) dilemmas. From this perspective, the present work contributions are multifold. First, we measured, on the same subjects, their CPR governance performance when exposed to EVs vis-à-vis their 'institutional robustness'. This combination of inputs offered insights for further understanding of CPR's governance theory and its linkages with 'institutional robustness', a highly contested question. Second, our findings might serve as a guideline for policymakers working with small-scale farmers confronted with environmental variability. Finally, we offer empirical evidence to Ostrom's DPs discussion, especially on the importance of conflict resolution mechanisms. Thus, the paper empirically contributes to understanding the associations between contextual and individual attributes-an unsolved academic claim e.g., [31,32]—framing conditions (social dilemmas under environmental uncertainty) and outcomes or payoffs of subjects' decisions when exposed to those framing conditions.

In the following section, we briefly review key elements of institutional robustness, focusing primarily on its conflict-resolution mechanisms. The third section, introduces the methodological approach, including an overview of the sampling strategy and the methodological decisions (for methodological details refer to Dipierri, unpublished manuscript). The paper continues with the next section where the key findings are presented, to then proceed with the last section where we discuss the findings and conclude the paper. In the latter, we elaborate on the theoretical and practical implications of this research and present future research avenues, based on our findings.

\section{Literature Review}

Shepsle [33] defines 'institutional robustness' as a situation where an institution's endurance results from the development of operational rules that are, eventually, modified over time. The modifications to the operational rules are introduced according to a set of collective-choice rules, which might themselves be modified slowly over time also [34]. For this paper, however, we embrace the contemporary and widely accepted definition by Carlson and Doyle: "the maintenance of some desired system characteristics despite fluctuations in the behavior of its component parts or its environment" 
(p. 2538, [35]) as it puts particular emphasis on complex systems such as SESs and its adaptability to disturbances such as environmental variability.

Ostrom [36], following North's [37] conception of 'institutions' as mechanisms for reducing uncertainty in complex and uncertain environments, laid out eight (8) key Design Principles (DPs) related to 'institutional robustness'. They were tailored to sustainably governed CPRs by reducing uncertainty and building trust and reciprocity. Then, collective action becomes possible. From this perspective, the DPs explain the conditions under which trust and reciprocity can emerge and be sustained to overcome social dilemmas embedded in CPRs [38] through collective action.

As these DPs have been extensively discussed in the literature $[18,34,36,39]$, we briefly mention them in Table 1:

Table 1. Design principles (DP) for governing sustainable resources derived from studies of long enduring institutions.

\begin{tabular}{|c|c|}
\hline Design Principle & Definition \\
\hline DP1. Clearly defined boundaries & $\begin{array}{l}\text { "The boundaries of the resource system (e.g., irrigation system or fishery) } \\
\text { and the individuals or households with rights to harvest resource units are } \\
\text { clearly defined." }\end{array}$ \\
\hline $\begin{array}{l}\text { DP2. Proportional equivalence } \\
\text { between benefits and costs }\end{array}$ & $\begin{array}{l}\text { "Rules specifying the amount of resource products that a user is allocated } \\
\text { are related to local conditions and to rules requiring labor, materials, and/or } \\
\text { money inputs." }\end{array}$ \\
\hline DP3. Collective choice arrangements & $\begin{array}{l}\text { "Most individuals affected by harvesting and protection rules are included } \\
\text { in the group that can modify these rules." }\end{array}$ \\
\hline DP4. Monitoring & $\begin{array}{l}\text { "Monitors, who actively audit biophysical conditions and user behavior, are } \\
\text { at least partially accountable to the users and/or are the users themselves." }\end{array}$ \\
\hline DP5. Graduated sanctions & $\begin{array}{l}\text { "Users who violate rules in use are likely to receive graduated sanctions } \\
\text { (depending on the seriousness and context of the offense) from other users, } \\
\text { from officials accountable to these users, or from both." }\end{array}$ \\
\hline DP6. Conflict resolution mechanisms & $\begin{array}{l}\text { "Users and their officials have rapid access to low-cost local arenas to } \\
\text { resolve conflict among users or between users and officials." }\end{array}$ \\
\hline $\begin{array}{l}\text { DP7. Minimal recognition of rights } \\
\text { to organize }\end{array}$ & $\begin{array}{l}\text { "The rights of users to devise their own institutions are not challenged by } \\
\text { external governmental authorities, and users have long-term tenure rights } \\
\text { to the resource." }\end{array}$ \\
\hline DP8. Nested enterprises & $\begin{array}{l}\text { "For resources that are parts of larger systems: Appropriation, provision, } \\
\text { monitoring, enforcement, conflict resolution, and governance activities are } \\
\text { organized in multiple layers of nested enterprises." }\end{array}$ \\
\hline
\end{tabular}

Source: Author's elaboration based on Ostrom (p. 33, [24]).

It is worth highlighting that the first five (5) DPs form a single coherent "block" of interconnected and interdependent principles. In Elinor Ostrom's own words:

"When the users of a resource design their own rules (design principle 3) that are enforced by local users or accountable to them (design principle 4) using graduated sanctions (design principle 5) that clearly define who has rights to withdraw from a well-defined resource (design principle 1) and that effectively assign costs proportionate to benefits (design principle 2), collective action and monitoring problems tend to be solved in a reinforcing manner". (p. 267, [18])

Gari et al. (p. 11, [39]) find that DP1 and DP2 are the most commonly present DPs, followed by DP3 and DP6, while DP4 and DP5 are less commonly reported. What is of particular interest for this paper is DP6: the importance of low-cost, swift, well understood, similarly interpreted, and effective conflict-resolution mechanisms within a community. This is seemingly supported by empirical evidence despite some inconsistencies in the findings [34]. However, it is our view that this DP (DP6) incorporates most of the criticism against the eight (8) DPs: their incompleteness, their wider applicability, their fundamental approach [38], and the poor cause-effect relationship 
between social-ecological 'institutional robustness' and CPR's governance [39]. Numerous studies argue that the DPs are rather descriptive and too case-specific to be employed as tools to understand 'institutional robustness': "[ ... ] from our study it has become clear that the real 'glue' that keeps an institution alive over time are the social mechanisms, i.e., trust, legitimacy, and transparency" (p. 251, [40]). External socioeconomic factors that can rapidly disturb and deteriorate a system are also particularly emphasized as totally missing from the DPs [38]. Notably Young [41] and Agrawal [42] argue that the DPs are formulated as 'laws' that should hold in every case regardless of other variables, which is not the case. It is interesting that Ostrom $[43,44]$ slowly distanced herself from the strict nature of the DPs and moved to a rather diagnostic approach.

Thus, our general hypothesis, based on the prevalent literature, is that institutionally robust SESs will cope better with external disturbances, such as EVs. In this line, a more specific working hypotheses signals that SESs with conflict-resolution mechanisms will be better equipped to cope with the environmental variations, without affecting their performance and endurance. Thus, in this paper, we dig deeper into the role of conflict-resolution mechanisms (DP6) and the strategies adopted by the SESs to overcome uncertainty.

The role of 'institutional robustness' in coping with EV is of particular importance for Latin America, where our case study is located. Because of heavy dependence on agriculture for livelihood and poor coping mechanisms to adapt to climatic challenges [45] or even mitigate them, the region is particularly vulnerable to environmental variability.

\section{Materials and Methods}

A field version of the irrigation dilemma game with environmental variations developed for a lab setting by Anderies et al. [46], and adapted by Dipierri [47] (the protocol used for this experiment is available in Dipierri [47]) for the water variation treatment was conducted in northern Argentina between 2016 and 2017. In total, we conducted six (6) sessions. Even though the number of sessions seems small at first sight, it is similar to the case study size of other field experiments working with this topic (p. 509, [48]; p. 67, [49]; p. 8, [50]; p. 15, [51]). It is also worth noticing that the experiment, as explained later in this paper, included several rounds, offering 1200 observations (600 investments, and 600 extractions) corresponding to 6 sessions of 5 subjects each that invested and extracted 20 times in each session.

The methodological strategy focused on the internal validity of the results rather than its external validity. We aimed at understanding in depth the collective actions we observed through a multimethod approach that included in-depth interviews with subjects and key informants, surveys, and non-participatory observation.

\subsection{Case Study}

Argentina, like most nations in the world, has been experiencing different phenomena associated with climate change. A recent study considering heat waves in Argentina between 1960 and 2010 concluded that their frequency has augmented, especially in the last decade, and they were strong in the northwest of Argentina [52]. Projection models report a continuation of this trend in the coming century [16]. Precipitations research also indicated a positive trend in the last decades, especially in the central regions of Argentina [17], with an exponential interannual variability [16]. As agriculture is environmentally dependent, the climate change phenomena have impacted the national production in different manners throughout the national territory [17]. While some regions (e.g., the Pampa region in the south) have reported an increased productivity thanks to the increased rainfalls, other regions (e.g., the northwest region) were negatively affected due to the droughts and floods as well as the increased temperatures that led to evaporation of the available water [16,17]. These diverting externalities of climate change in agriculture are particularly important in Argentina, where the sector represents $63.7 \%$ of the country export revenues [53]. 
As projections indicate that this polarization among regions will stress [54], we have decided to focus on the Northwest region of Argentina. This region had the largest share of the irrigated field in the country in 2011, and this position has increased consistently [55]. With two well-defined seasons, the rainy season (summer and autumn) and dry season (winter and spring), irrigation water management in the region is crucial for guaranteeing water access and use during the dry season. The seasonality of rainfall is expected to intensify in the upcoming decades (p. 38, [56]). This implies that, in the dry season, when the demand for water from small-scale farmers peaks, water uncertainties might surge; while during the rainy season the excessive water might harm the crops and/or destroy their precarious communal irrigation systems.

Water management in the region is heterogeneous with formal and informal schemes co-existing. In both cases, water is normally distributed through shifts only during the dry season, and the irrigation infrastructure used to distribute the water is rustic (the irrigation infrastructure has small doors, dikes built with rocks, and the channels are non-laminated). Therefore, the efficiency of the irrigation system in Jujuy, one of Northwest Argentinian states, is low (p. 44, [57]).

For this research, the irrigation systems were the units of analysis and the small-scale farmers were the units of information. Given the need to create trust with the small-scale farmers before the sessions could be conducted, the sampling was finalized in cooperation with the 'Instituto Nacional de Tecnología Agropecuaria'. The final decision was to work in the south region of the Jujuy Province (see Figure 1).

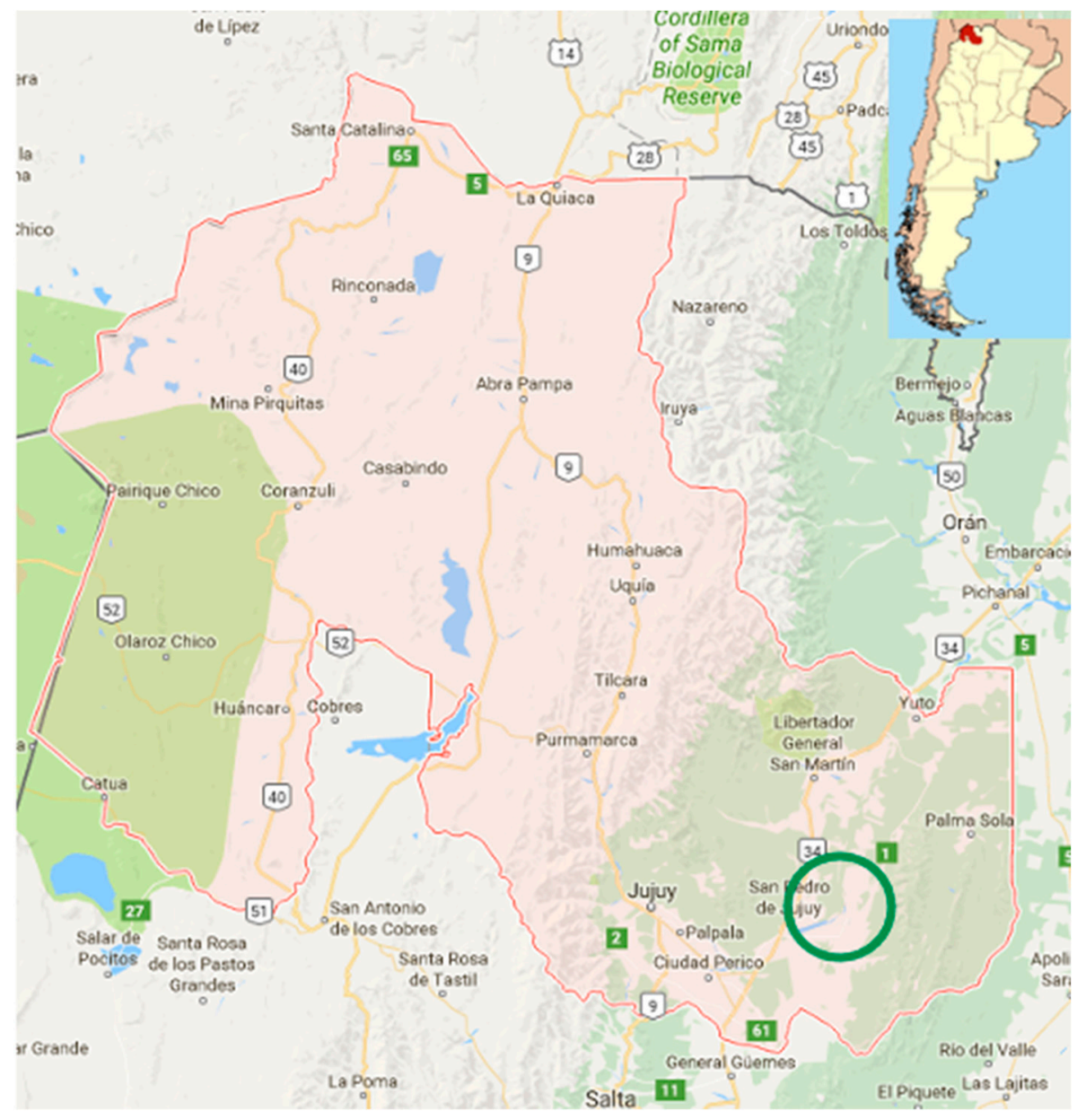

Figure 1. Jujuy's Yungas region, Argentina-Case Study. Source: Author's elaboration based on Google Maps. 


\subsection{Frame-Field-Experimental Setting}

In total six (6) framed-field sessions were conducted with small scale farmers (from now onwards also referred to as 'subjects') from two (2) small irrigation systems located in the same area. This consideration was relevant, as it has been shown that group size affects CPR governance [39]. Our sampling strategy was to group the subjects in a way that different levels of 'institutional robustness' were represented. More specifically, farmers from four (4) of the six (6) groups belong to an agricultural cooperative or association, while the remainder did not. All the subjects from a group belong to the same cooperative or association, and shared the same irrigation system in the field.

In each session, farmers were assigned a fixed position in the irrigation system (asymmetric positions ranged from A-upstream position, near the water source, to E-downstream position, away from the water source). Each session lasted 20 rounds divided into two sets: (i) stable or baseline and (ii) unstable. During the first set (from round 1 to 10) irrigation water was constant in all the rounds. Water variations, with the same fluctuation as in the seminal paper [46], were introduced in the second set (from round 11 to 20).

In each of the 20 rounds, farmers could collect points through two (2) channels, as explained in detail later in this paper: (i) tokens not invested in the system's maintenance and (ii) crops produced with the water extracted.

Each round had three (3) stages: (i) cheap talk, (ii) investment, and (iii) extraction. First, subjects could (i) talk openly for a minute with no restriction of topics, except the typical caveats of no threats and no aftermath payments propositions. During this stage, the subjects were given time to craft their CPR governance rules. Thus, different from previous field experiments working with water governance where rules are exogenously imposed [48,50], at list partially, in our experimental setting, and in all the sessions, the rules to govern their CPR were endogenously crafted by the subjects.

In the second stage, each subject received 10 tokens at the beginning of each round and (ii) they were asked to individually and privately decide the number of tokens they wanted to invest $\left(\mathrm{INV}_{\mathrm{t}}\right)$ on the irrigation system maintenance. To simulate the pass of time, the system deteriorated 25 percentage points ( 1 percentage point equaled 1 token) in every round. If the irrigation system capacity was below 45 percentage points, no water would be distributed, because the system would be considered as 'collapsed'. Thus, if in successive rounds the collective investment was not enough to compensate for the deterioration (collective investment $<25$ tokens), no water was distributed. Subjects were confronted with the typical 'provision problem' because each non-invested token (10-INV $\mathrm{I}_{\mathrm{t}}$ added to their individual payoff (individual payoff from not investing in the irrigation system). In the third stage, each subject could (iii) extract water from the irrigation system but as water moved from upstream to downstream positions, lower positions only received the water not used by subjects in upper positions. The total amount of water units for distribution in each round depended not only on the irrigation system capacity (collective investment from stage two) but also from the water available in that round (constant between round 1 and 10 and variable between round 11 and 20). The competition exacerbated because the maximum crop production (private earnings) was achieved with 20 water units. Less than 20 water units implied that the crops had not received enough water and more than 20 water units implied that the crops were overwatered (diminishing returns). However, this objective (20 water units) was untenable to all subjects simultaneously, because there was not water enough for everyone. Additionally, while investment was private, water extraction was public, mimicking reality. To make it public, each unit of water was represented with a blue card. For example, if 60 units of water were available, 60 blue cards were handed over to the subject in position A, then subject A extracted the number of water units (blue cards) wished and passed the remaining water units (blue cards) to subject $\mathrm{B}$, and so forth. The amount of water extracted by each subject determined the number of crops that this particular subject could produce.

In sum, in each round individual payoff or net gains $\left(\mathrm{NG}_{\mathrm{t}}\right)$ resulted from the tokens not invested $\left(10-\mathrm{INV}_{\mathrm{t}}\right)$ in the irrigation system maintenance plus the income from crop production $\left(\mathrm{INC}_{\mathrm{t}}\right)$. Subjects were paid one (1) peso for each non-invested token and each produced crop. At the end 
of the session, the total amount of points was converted into pesos, and subjects were paid in cash. For example, if a subject had collected 100 points he was paid 100 Argentinian pesos.

Each session included two (2) trial rounds, and the subjects played them before the first set. Additionally, we conducted a quiz to assess the level of understanding of the game. During the explanation of the experiment, the trial rounds, and the 'understanding quiz', we encouraged subjects to raise clarification questions that we answered publicly before the protocol continued.

This game setting had two (2) potential extreme scenarios, as well as all the possibilities between the extremes: Nash Equilibrium (NE) and Social Optimal (SO). The NE implied that subjects behaved selfishly and did not cooperate. Upstream players invested the minimum required to secure water for themselves. As the minimum threshold investment of 25 tokens per round to compensate for the deterioration was not reached, then the irrigation system collapsed after the third round. In terms of extraction, subjects upstream extracted 20 water units in the first and second round (the amount of water that offered them the highest return on investment), leaving no water to subjects downstream. In the third round, only subject A was able to extract water. In the following rounds, no water was distributed because the irrigation system had deteriorated. A similar pattern occurred in the second set with environmental variability.

On the contrary, in a cooperative scenario (Social Optimal), subjects were able to invest in a fair manner aiming at keeping the irrigation system capacity at the social-optimal threshold of $66 \%$. Thus, from the third round onwards, each subject invested five (5) tokens that collectively compensated the irrigation system deterioration. Similarly, extraction was also equally distributed among the subjects, each obtaining 12 water units in the first set of rounds. During the second set, the amount of water available varied in between rounds. However, water available was distributed equally among subjects, even in droughts simulations.

Table 2 presents an overview of the game setting.

Table 2. Experimental setting summary. The frame-field experiment setting conducted is presented in brief.

\begin{tabular}{ll}
\hline Participants & 5 per session \\
\hline Positions & A (upstream) to E (downstream) \\
\hline Rounds & 20 \\
\hline First set & Rounds 1-10 without environmental variability (stable water flow) \\
\hline Second set & Rounds 11-20 with environmental variability (unstable water flow) \\
\hline Stages per round & $\begin{array}{l}\text { Stage 1: 'Cheap-talk' for one minute } \\
\text { Stage 2: Private investment decision } \\
\text { Stage 3: Public water extraction decision }\end{array}$ \\
\hline Action-outcome linkages & $\begin{array}{l}\text { The capacity of the irrigation system depended on the collective } \\
\text { investment, the irrigation system depreciation, and the previous round } \\
\text { irrigation system capacity. } \\
\text { The amount of water extracted by upstream subjects affected the } \\
\text { amount of water available for downstream subjects. } \\
\text { The amount of water available to subjects downstream might affect their } \\
\text { contribution in the following rounds. }\end{array}$ \\
\hline $\begin{array}{l}\text { Nash-Equilibrium: subjects do not invest, the infrastructure deteriorates, } \\
\text { and it does not distribute water. Each player earns 10 tokens per round. } \\
\text { Social-Optimal: collective investment keeps the irrigation system at the } \\
\text { optimal capacity and water is distributed. Each player earns from the } \\
\text { non-invested tokens and the crops produced. }\end{array}$ \\
\hline $\begin{array}{l}\text { All the players had the same information. } \\
\text { Outcomes }\end{array}$ \\
\begin{tabular}{l} 
Source: Authors' elaboration based on Ostrom [18]. \\
\hline
\end{tabular}
\end{tabular}




\subsection{Complementary Methods}

In addition to the framed-field experiments, a survey was carried out among the entire sample. It included production settings, living conditions, and socio-demographic information. In particular, we asked participants to assess their communal irrigation systems' 'institutional robustness'. To develop the statements, we built on Ostrom's Design Principles (DPs). The seventh and eighth DPs were not included in this self-assessment, as they are to be answered by levels of governance above the irrigation systems (p. 77, [58]). Self-reported perceptions tools such as our survey have proved to report satisfactory levels of reliability and validity [59].

Each of the first six (6) DPs were measured with a five (5) points Likert scale ranging from 'totally disagree' to 'totally agree' (see Table 3). Following Gari et al. [39], who propose a scale from 'absence' (0) to 'present' (1) of the DPs, we coded the answers ranging from 'total disagreement' (0) to 'total agreement' (1). We also considered intermediate answers with 0.25 for 'disagreement', 0.5 for 'neutral', and 0.75 for 'agreement'. Then, the level of 'institutional robustness' was calculated as a cumulative result of the DPs values. For comparability purposes with Gari et al. [39], all DPs had the same weight and the total score was rescaled to six (6) DPs with four (4) potential outcomes: 'failed', 'fragile', 'weak', and 'successful'.

Table 3. Coded values for DPs based on the Likert scale, and potential outcomes.

\begin{tabular}{cccc}
\hline DPs Category & Value & Total Score & Outcome \\
\hline Totally disagree (TD) & 0.00 & $0.0-2.2$ & Failed \\
Disagree (D) & 0.25 & $2.3-2.9$ & Fragile \\
Neutral (N) & 0.50 & $3.0-3.7$ & Weak \\
Agree (A) & 0.75 & $3.8-6.0$ & Successful \\
Totally Agree (TA) & 1.00 & & \\
\hline
\end{tabular}

Source: Adapted from Gari et al. (p. 4, [39]).

Finally, we conducted 27 in-depth interviews with key informants including technical advisors, government officials, and of course the subjects. In the latter case, we were particularly interested in the participants that reflected an outstanding behavior (over or under investment and over or under extraction).

\section{Results and Findings}

In this section, we present the results obtained in our fieldwork and triangulate the multimethod approach to test our guiding hypothesis: the higher the 'institutional robustness', and in particular, the conflict resolution mechanism (DP6), the better the performance under environmental variability.

In the first subsection, we present the descriptive statistics of our sample to then proceed with the general outcomes of the experimental sessions, with a focus on the groups' performance. Then, we triangulate these results with the self-reported 'institutional robustness' survey, and the in-depth interviews to test our hypothesis.

\subsection{Descriptive Statistics}

On average, subjects that participated in the framed-field experiment had $1.5(S D=1.2)$ hectares for their agricultural activities, $43 \%$ were female, and $7 \%$ were illiterate (see Table 4 ). Some outstanding elements from the survey are that three (3) of the six (6) groups reported to live and work in the same place and two (2) of the six (6) groups (G3 and G6) had used irrigation systems for fewer years $(M=12.3$, $S D=8.3)$ and lived in the area fewer years than the sample average $(M=21.4, S D=15.5)$. These groups also reported a lack of formal institutional arrangements such as cooperatives or associations. Thus, they were classified as 'non-organized' groups (G3 and G6), in opposition to the remaining groups (G1, G2, G4, and G5) that were classified as 'organized'.

Individual net gains (net gains $\left(\mathrm{NG}_{\mathrm{i}}\right)$ resulted from tokens not invested (10-INV $\left.\mathrm{It}_{\mathrm{it}}\right)$ on the infrastructure and the tokens earned from growing $\left(\mathrm{INC}_{\mathrm{it}}\right)$ crops in all the rounds (Section 3.2 
Frame-field-experimental setting) ranged from 134 to 434 tokens $(M=333.0)$; while at a group level they accumulated between 1469 and 1889 tokens $(M=1665.0, S D=68.5)$. Per subject, the investment had a greater spectrum with a minimum of 13 and a maximum of 119 tokens $(M=89.7)$. At a group level, the behavior was more homogenous $(M=448.0, S D=20.6)$. Finally, the comprehension quiz after the two (2) trial rounds showed a quite robust understanding of the game. On average, $94 \%$ of the subjects gave the right answers.

Table 4. Group socio-economic features and overall performance.

\begin{tabular}{|c|c|c|c|c|c|c|c|}
\hline Variable & G1 & G2 & G3 & G4 & G5 & G6 & Average \\
\hline Female & $20 \%$ & $40 \%$ & $40 \%$ & $0 \%$ & $60 \%$ & $100 \%$ & $43.33 \%$ \\
\hline Illiterate & $20 \%$ & $20 \%$ & $0 \%$ & $0 \%$ & $0 \%$ & $0 \%$ & $6.66 \%$ \\
\hline Age & $\begin{array}{c}57.2 \\
(6.97)\end{array}$ & $\begin{array}{c}58.6 \\
(15.33)\end{array}$ & $\begin{array}{l}51.0 \\
(3.76)\end{array}$ & $\begin{array}{c}47.0 \\
(5.50)\end{array}$ & $\begin{array}{c}34.0 \\
(6.85)\end{array}$ & $\begin{array}{c}35.0 \\
(4.07)\end{array}$ & $\begin{array}{c}47.1 \\
(12.63)\end{array}$ \\
\hline Hectares & $\begin{array}{c}1.8 \\
(1.28)\end{array}$ & $\begin{array}{c}1.6 \\
(0.86)\end{array}$ & $\begin{array}{c}1.8 \\
(2.14)\end{array}$ & $\begin{array}{c}0.9 \\
(0.20)\end{array}$ & $\begin{array}{c}1.3 \\
(0.60)\end{array}$ & $\begin{array}{c}1.6 \\
(0.86)\end{array}$ & $\begin{array}{c}1.5 \\
(1.20)\end{array}$ \\
\hline Household members & $\begin{array}{c}6.4 \\
(2.95) \\
\end{array}$ & $\begin{array}{c}5.8 \\
(2.23) \\
\end{array}$ & $\begin{array}{c}4.39 \\
(0.50) \\
\end{array}$ & $\begin{array}{c}5.48 \\
(1.69) \\
\end{array}$ & $\begin{array}{c}5.0 \\
(1.68) \\
\end{array}$ & $\begin{array}{c}5.2 \\
(0.98) \\
\end{array}$ & $\begin{array}{c}5.38 \\
(1.95) \\
\end{array}$ \\
\hline Live in the area & $40 \%$ & $40 \%$ & $40 \%$ & $100 \%$ & $100 \%$ & $100 \%$ & $70 \%$ \\
\hline $\begin{array}{l}\text { Years in the same } \\
\text { place }\end{array}$ & $\begin{array}{c}27.8 \\
(13.34) \\
\end{array}$ & $\begin{array}{c}31.4 \\
(11.97) \\
\end{array}$ & $\begin{array}{c}28.0 \\
(17.44) \\
\end{array}$ & $\begin{array}{c}36.2 \\
(16.66)\end{array}$ & $\begin{array}{c}22.4 \\
(12.15)\end{array}$ & $\begin{array}{c}21.4 \\
(14.47) \\
\end{array}$ & $\begin{array}{c}27.87 \\
(15.30) \\
\end{array}$ \\
\hline $\begin{array}{l}\text { Institutional } \\
\text { Arrangements }\end{array}$ & YES & YES & $\mathrm{NO}$ & YES & YES & $\mathrm{NO}$ & \\
\hline Trust & $\begin{array}{c}4.8 \\
(0.40)\end{array}$ & $\begin{array}{c}4.4 \\
(0.80)\end{array}$ & $\begin{array}{c}3.8 \\
(0.98)\end{array}$ & $\begin{array}{c}4.6 \\
(0.49)\end{array}$ & $\begin{array}{c}3.6 \\
(1.75)\end{array}$ & $\begin{array}{c}3 \\
(1.42)\end{array}$ & $\begin{array}{c}4.03 \\
(1.25)\end{array}$ \\
\hline $\begin{array}{l}\text { Average investment } \\
\text { per round and subject }\end{array}$ & $\begin{array}{c}4.68 \\
(1.39)\end{array}$ & $\begin{array}{c}4,41 \\
(1.98)\end{array}$ & $\begin{array}{c}4.31 \\
(2.52)\end{array}$ & $\begin{array}{c}4.66 \\
(2.06)\end{array}$ & $\begin{array}{c}4.55 \\
(1.57)\end{array}$ & $\begin{array}{c}4.31 \\
(2.07)\end{array}$ & $\begin{array}{c}4.49 \\
(1.96)\end{array}$ \\
\hline $\begin{array}{l}\text { Average extraction } \\
\text { per round and subject }\end{array}$ & $\begin{array}{l}11.96 \\
(3.01)\end{array}$ & $\begin{array}{l}10.08 \\
(4.73)\end{array}$ & $\begin{array}{l}10.92 \\
(4.35)\end{array}$ & $\begin{array}{c}9.88 \\
(4.04)\end{array}$ & $\begin{array}{l}11.75 \\
(2.28)\end{array}$ & $\begin{array}{l}9.76 \\
(3.99)\end{array}$ & $\begin{array}{l}10.72 \\
(3.91)\end{array}$ \\
\hline $\begin{array}{l}\text { Average earnings per } \\
\text { round per subject }\end{array}$ & $\begin{array}{c}18.6 \\
(5.54)\end{array}$ & $\begin{array}{l}15.54 \\
(6.44)\end{array}$ & $\begin{array}{l}16.64 \\
(7.43)\end{array}$ & $\begin{array}{l}14.69 \\
(6.81)\end{array}$ & $\begin{array}{l}18.89 \\
(4.25)\end{array}$ & $\begin{array}{l}15.58 \\
(6.56)\end{array}$ & $\begin{array}{l}16.65 \\
(6.43)\end{array}$ \\
\hline Comprehension Quiz & $\begin{array}{c}92 \% \\
(1.17)\end{array}$ & $\begin{array}{c}98 \% \\
(0.40)\end{array}$ & $\begin{array}{c}90 \% \\
(0.90)\end{array}$ & $\begin{array}{c}92 \% \\
(0.75)\end{array}$ & $\begin{array}{c}92 \% \\
(1.17)\end{array}$ & $\begin{array}{l}98 \% \\
(0.40)\end{array}$ & $\begin{array}{c}94 \% \\
(0.91)\end{array}$ \\
\hline
\end{tabular}

Notes: In parenthesis the Standard Deviation. Source: Authors.

\subsection{Experimental Performance}

It is important to highlight that the experiment was used to identify the "best-performing groups" to then inform the subsequent qualitative analysis of 'institutional robustness'. Therefore, we will limit the presentation of the experimental results to the minimum only to allow the understanding of how group performance and 'institutional robustness' was approached, as well as how it relates to each of the groups.

Figure 2 summarizes the tokens investment and water extraction behavior per group comparing the first set (Round 1 to 10: R1-10), when water was stable, with the second set (Round 11 to 20: R11-20), when water varied from round to round. Our results show that G1 (Group) and G5 increased their investment during environmental variation (R11-20), and were the groups that invested the most during this set. We also observed that these groups (G1 and G5) were able to extract more than the other groups during both sets. They also had a smaller average standard deviation than the other groups, for both sets in the investment and extraction process.

The investment and extraction behaviors reflected on the groups' net gains (Figure 3) with G1 and G5 obtaining the higher total net gains. The decline in their net gains between R1-10 and R11-20 
can be explained by the higher experimental setting complexity of the second set (R11-20) and the shortage of water during the rounds that mimicked droughts. We also observed that in these two (2) groups the earnings' asymmetry was smaller than in other groups, except G6 that also reported a low average standard deviation.

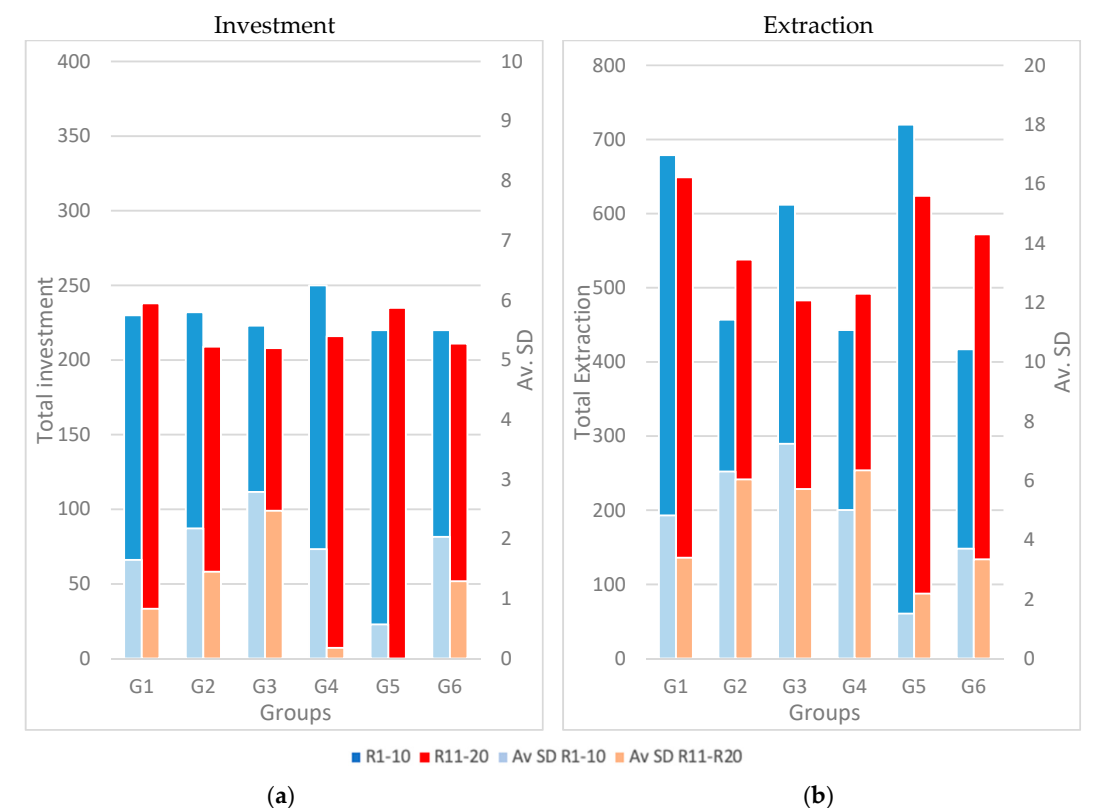

Figure 2. Total investment and extraction per set by group. The graph shows the total group investment (panel a) and the total water extraction (panel b) of each group and its evolution, comparing R1-10 to R11-20. The average standard deviations among subjects per round for the investments and extraction are also presented. Notes: Round 1 to 10 (R1-10); Round 11 to 20 (R11-20); Average Standard Deviation (Av SD). Source: Authors.

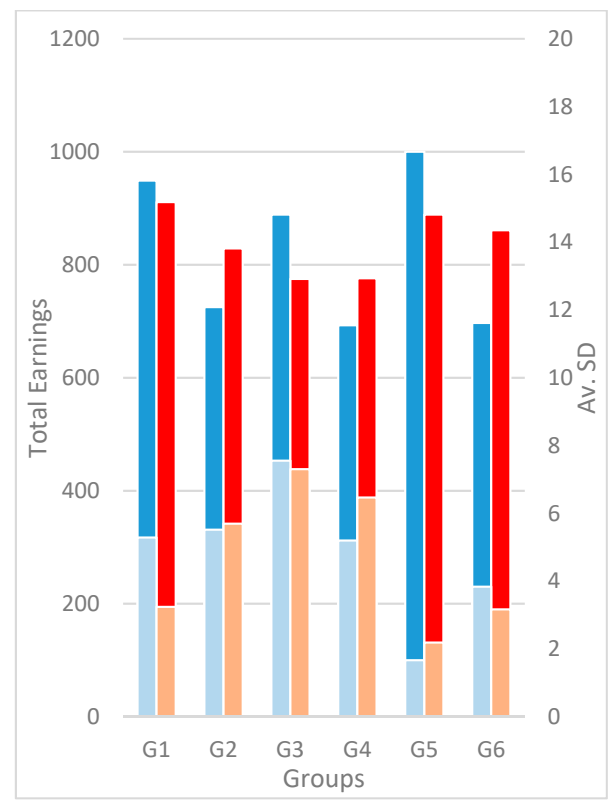

- R1-10 $\approx$ R11-20 $\mid$ Av SD R1-10 $=$ Av SD R11-R20

Figure 3. Total Net Gains per set by group. The graph shows the total Net Gains per group and their evolution, from R1-10 to R11-20. It also shows the Net Gains average standard deviations. Notes: Round 1 to 10 (R1-10); Round 11 to 20 (R11-20); Average Standard Deviation (Av SD). Source: Authors. 
Finally, we assessed the movement from Non-cooperation (Nash-Equilibrium $=0$ ) to Cooperation (Social-Optimal $=100$ ), by measuring to what extent the Net-Gain (NG) exceeded the Nash-Equilibrium $(\mathrm{NE})$, related to the difference between the Social-Optimal (SO) and the NE, following John M. Anderies et al. [46]. This is:

$$
\% \text { increase }=(\mathrm{NG}-\mathrm{NE}) /(\mathrm{SO}-\mathrm{NE})
$$

The NE, as explained earlier, was calculated considering selfish subjects that did not invest in the irrigation system maintenance, except to guarantee themselves water in future rounds. Thus, the irrigation system deteriorated rapidly, and the subjects only earned 10 tokens per round (the 10 tokens that were given to them in each round). The $\mathrm{SO}$, also explained before, was calculated considering that the subjects invested in a collaborative manner, keeping the irrigation system at the SO level of $66 \%$ and were able to evenly distribute all the water available in each round.

As shown in Table 5, we found that the groups with a better collective action performance, in both sets, were G1 and G5. Both groups reported to be closer to the SO outcome than other groups, even when exposed to water variability (second set-R11-20).

Table 5. Cooperation per set by group. The table shows the distance between the Nash Equilibrium (NE) and the Net Gain (NG). The higher the percentage, the higher the level of cooperation.

\begin{tabular}{ccccccccccccc}
\hline & \multicolumn{3}{c}{ R1-10 } & \multicolumn{1}{c}{ R11-20 } & \multicolumn{3}{c}{ R1-20 } \\
\cline { 2 - 13 } & NG & N.E. & S.O. & \% Increase & NG & N.E. & S.O. & \% Increase & NG & N.E. & S.O. & $\%$ Increase \\
\hline G1 & 949 & 609 & 1034 & $80 \%$ & 911 & 607 & 897 & $105 \%$ & 1860 & 1216 & 1931 & $90 \%$ \\
\hline G2 & 725 & 609 & 1034 & $27 \%$ & 829 & 607 & 897 & $77 \%$ & 1554 & 1216 & 1931 & $47 \%$ \\
\hline G3 & 889 & 609 & 1034 & $66 \%$ & 775 & 607 & 897 & $58 \%$ & 1664 & 1216 & 1931 & $63 \%$ \\
\hline G4 & 693 & 609 & 1034 & $20 \%$ & 776 & 607 & 897 & $58 \%$ & 1469 & 1216 & 1931 & $35 \%$ \\
\hline G5 & 1000 & 609 & 1034 & $92 \%$ & 889 & 607 & 897 & $97 \%$ & 1889 & 1216 & 1931 & $94 \%$ \\
\hline G6 & 697 & 609 & 1034 & $21 \%$ & 861 & 607 & 897 & $88 \%$ & 1558 & 1216 & 1931 & $48 \%$ \\
\hline \multicolumn{3}{c}{ Notes: Nash-Equilibrium = (NE); Social-Optimal = SO. Source: Authors. } &
\end{tabular}

\subsection{Institutional Robustness}

According to Anderies et al. [23], greater robustness of SESs ensures better performance when confronted with disturbances. It is also in line with Gari et al.'s [39] findings indicating that successful SESs are those that accomplish not only long-lasting survival but that, when confronted with external disturbances, such as the EVs we introduced in the second set of the framed-field experiment, they also accomplish their objectives. Consequently, we expected that better-performing groups (G1 and G5) would report higher 'institutional robustness'.

To explore this premise, we asked the subjects to self-assess their 'institutional robustness' using a Likert Scale as part of the survey (for methodological precisions see Dipierri [47]). Although all results presented in this section reflect the subjects' opinion, the results were in line with information collected through the in-depth interviews to the subjects and the technical advisors as well as the field observations.

As shown in Figure 4 and Table 6, three (3) of the six (6) groups (G1, G2, and G4) reported a 'successful' 'institutional robustness'. These groups also reported higher levels of trust, confirming the link between robustness and trust argued by (p. 12, [23]).

Now, looking particularly at the best performing groups (G1 and G5), we find contrasting results. While subjects from G1, reported a 'successful' 'institutional robustness', in line with Anderies et al.'s [23] results; subjects from G5 reported a 'fragile' 'institutional robustness'. These contradictory results do not allow us to confirm our hypothesis. Thus, we decided to go one step further and search for potential explanations analyzing each Design Principles (DP). With this purpose, we triangulated the survey results, the in-depth information gathered during the interviews, the group discussions, and the 
non-participatory observation. The information source is presented in parenthesis, indicating 'farmer' or 'informant' followed by an ID number to protect their identities.

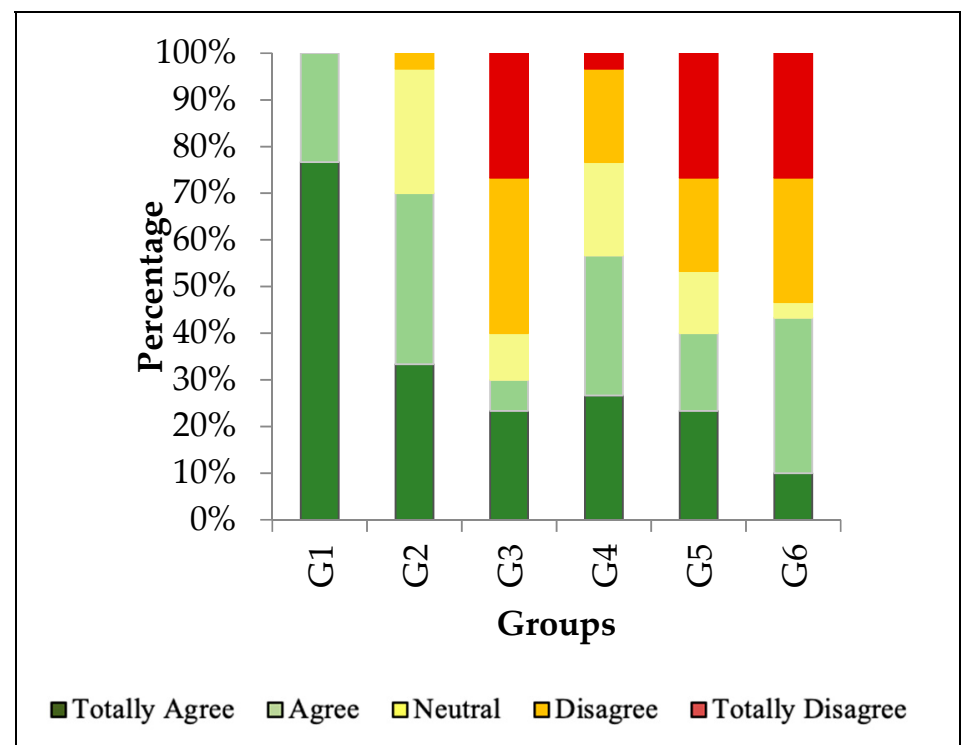

Figure 4. Self-assessed institutional robustness per group. The overall level of robustness is presented as a summary of the Design Principles reported by the participants. Source: Authors.

Table 6. Group socio-economic features and overall performance.

\begin{tabular}{cccccccc}
\hline Variable & G1 & G2 & G3 & G4 & G5 & G6 & Sample Average \\
\hline DP 1 & 0.95 & 0.80 & 0.60 & 0.70 & 0.85 & 0.65 & 0.76 \\
DP 2 & 0.95 & 0.85 & 0.45 & 0.75 & 0.75 & 0.85 & 0.77 \\
DP 3 & 0.90 & 0.80 & 0.20 & 0.75 & 0.45 & 0.35 & 0.58 \\
DP 4 & 1.00 & 0.80 & 0.45 & 0.50 & 0.25 & 0.40 & 0.57 \\
DP 5 & 0.85 & 0.45 & 0.45 & 0.60 & 0.20 & 0.25 & 0.47 \\
DP 6 & 1.00 & 0.80 & 0.50 & 0.55 & 0.40 & 0.50 & 0.55 \\
Robustness & 5.65 & 4.50 & 2.65 & 3.85 & 2.85 & 2.60 & \\
& Successful & Successful & Fragile & Successful & Fragile & Fragile & \\
\hline
\end{tabular}

Source: Authors.

However, before continuing it is worth noticing that in general, and as expected, organized groups (G1, G2, G4, and G5) agreed more with the DP's statements than non-organized groups (G3 and G6).

The first Design Principle (DP1-'well-defined boundaries') seems to be better defined in G1, G2, and G5 (Figure 5). Indeed, these two (2) groups performed better throughout the sessions with high levels of investment and low average standard deviations in their investment, extraction, and earnings (see the Results' section). Elaborating on these results, subjects from G1 and G2 explained that they know who belongs to their irrigation system and what their obligations and rights are. They also indicated that when someone does not participate in the maintenance, this person must compensate the group members. For example, if someone does not participate in the general maintenance of the system, then for the next maintenance round two persons from their household must participate, or they are granted it read reduced access to water. These are clear indications that the boundaries of these groups are very well defined. Furthermore, and in line with Ostrom's (p. 32, [24]) argumentation, the poor boundaries reported by non-organized groups (G3 and G6) could partially explain the free-riding cases observed during the framed-field experiment.

Theoretically, with clear boundaries (DP1), the equivalence between the costs and benefits (DP2) obtained from being part of the social-ecological systems (SESs) could be better assessed by users. Hence, their willingness to comply with the rules, would be enhanced (p. 34, [24]). Unexpectedly, a nonorganized group (G6) assessed their 'costs and benefits' DP as high. A potential explanation for this contradiction is that subjects in G6 did not expect benefits in their actual situation, while for 
organized groups (G1, G2, G4, and G5) expectations were high. The role and direction of expectations are a relevant element to consider explicitly in future 'institutional robustness' assessments. If the expected benefits are low and the costs are low, then the equivalence is reached. However, this might be a misleading assertion.

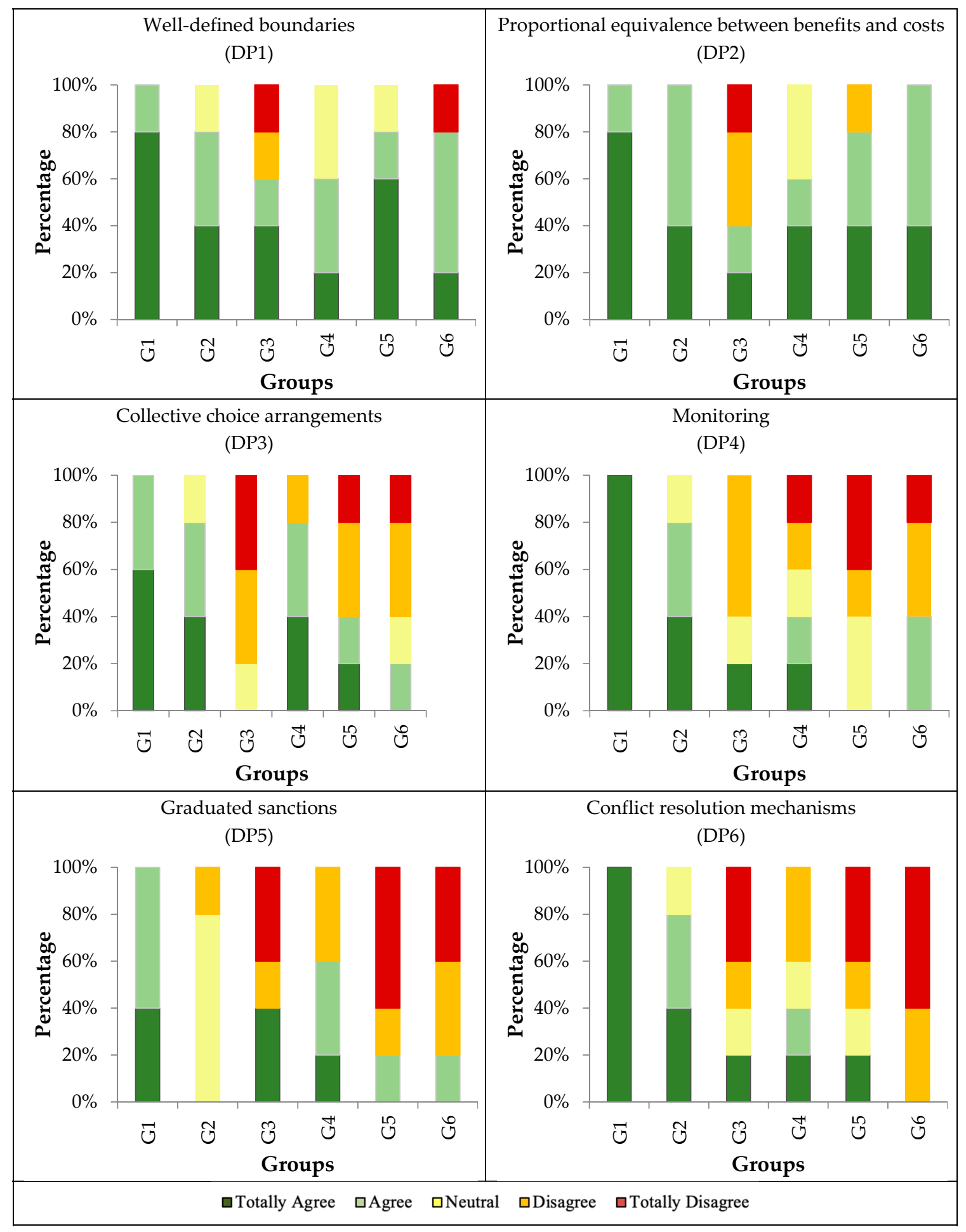

Figure 5. Self-assessed institutional robustness by Design Principle (DP) per group. The proportional group self-assessment of each design principle is presented per group of subjects. Source: Authors. 
The relevance of collective choice arrangements (DP3) is that their absence seems to lead to SESs' failure (p. 9, [38]). In this case, the empirical evidence showed two (2) clear scenarios: (i) the organized groups (G1, G2, G4, and G5) agreed more with the statement than (ii) the while for organized groups (G3 and G6). An obvious explanation might be that organized groups have developed several collective action rules while non-organized groups lack this feature. However, considerable discrepancies emerged among organized groups (G1, G2, G4, and G5). Subjects in G1 and G2 reported during the interviews that they self-crafted their institutional arrangements, that their decisions were voted during their monthly meetings based on a ' 50 plus one' rule (informants 21,26 , and 6). One of the authors had the privilege to participate in one of these meetings and confirmed the voting system and democratic participation of all the members. The latter strategy allowed them to bypass the lack of efficiency that Huntjens et al. (p. 73, [60]) argued might emerge when participation is required. On the contrary, subjects in G4 and G5 are impeded to fully develop their collective-choice arrangements. This happens because their plots are within the boundaries of a large farm, and the farm administration mediates the irrigation rules (informants 6 and 27, farmers 40 and 25). Finally, regarding the non-organized groups (G3 and G6), they emphasized that no institutional arrangements are governing their irrigation systems. They reported that the lack of 'collective arrangements' is such that downstream farmers, who invested in the irrigation system maintenance alone, sometimes do not receive water because upstream farmers, that did not invest in the irrigation system maintenance, extract all the water available.

The differences between the groups are more evident in the last three (3) Design Principles (DPs). G1 and G2 report agreement with the 'monitoring' system (DP4) statement, while G3, G4, G5, and G6 disagreed with it. Similarly, the 'graduated sanctions' (DP5) statement registered the most diverse assessments. Intriguingly, one of the groups that reported the highest disagreement was the group with the best performance during the session (G5). During the individual interviews with the subjects from G5, they explained that they did not develop a 'sanctions system', and problems are resolved on a one-to-one basis. As explained before, their 'collective choice arrangements' are intervened by the farm administration. The same situation was also reported by the key informants consulted. Thus, the qualitative information obtained through the interviews endorses the survey self-reported level of 'institutional robustness' and the corresponding Design Principles (DPs). Furthermore, several cases of violence occurred (farmer 25), probably due to the lack of 'conflict resolution mechanisms' (DP6) in the case of G5. For instance, G1 and G2 agreed with the 'conflict resolution mechanisms' (DP6) statement, while all the remaining groups disagreed. In this regard, subjects from G1 and G2 explained during the interviews that before the establishment of the 'Water Association' (understood as a nonprofit organization where members coordinate irrigation water governance), conflicts often emerged and sometimes escalated to violence (informants 27, 6, and 22), similarly to the other groups at the moment of the fieldwork. However, as they developed their institutional arrangements, conflicts decreased in G1 and G2, and currently, if they emerge, they are solved using their endogenously developed sanctioning system. Nevertheless, this robustness might come at the cost of much-needed flexibility to adapt their strategies to changing environmental conditions. Whether these endogenous developed rules have created fragilities in the SESs or not, requires further analysis. Contrariwise, the exogenously imposed rules by the farm administration in G4, G5, and G6 might be negatively affecting the SESs development, as suggested by several authors [51,61-63], due to incomplete information and a lack of understanding of local needs by the farm administration.

The results obtained in the Design Principles analysis presented also reject the hypothesis that groups with developed conflict resolution mechanisms will perform better under uncertainty. Hence, the groups' good performance during the session, even when lacking conflict resolution mechanisms (e.g., G5), could be explained by the fact that (i) they live and work in the same space sharing a high level of trust, (ii) they are all younger farmers, (iii) they rely on direct and efficient communication, and (iv) they have long experience of collective action (sharing among others: machinery, working-tools, and social benefits). 


\section{Discussion}

Our results support the guiding hypothesis, stating that institutionally robust groups perform well under environmental variability, while groups lacking appropriate institutional arrangements-in line with Ostrom's design principles (DPs) - are more exposed to the effect of external disturbances, as shown in other studies (p. 496, [64]). However, we also find that groups lacking conflict-resolution mechanisms are still able to successfully cooperate and avoid conflicts, even under conditions of increased uncertainties. It might be explained by a higher level of pre-existing trust $[64,65]$ in combination with certain socio-demographic variables like age, living settings, and working conditions that allow them to quickly deliberate, and effectively communicate adapting to new challenges, the 'new normal', as well as previous experiences with CPR management for governance.

The importance of these variables found in our study further contributes to the "incompleteness" of the DPs discussed in the critical literature and most notably articulated in Agrawal [42] and Cox et al. [38]. The observed diverging characteristics of groups, despite converging performances (especially between G1 and G5), further illustrate the importance of social relationships and the integrated power relationships as enacting elements of successful CPR governance and 'institutional robustness' [65].

It is possible to assume here that G1 relies much more on successful and long-surviving water governance practices (for example, over-investing to have a highly developed communal irrigation system-a "better safe than sorry" strategy—allowing them to mitigate the effect of uncertainties). This is achieved by the group's willingness to share the additional economic burden of such a strategy for the sake of increased security. Mitigation, in this case, is costly, as resources are wrongly allocated (over-invested) in the irrigation systems' maintenance. We also observe, in this case, the power relations that serve as an incentive to invest [64]. Overall, G1 seems to have strong institutional arrangements, but its flexibility to adapt to changing environments seems to be underdeveloped, as the group maintains the observed strategy regardless of the changing conditions. Thus, their strong institutional arrangements bring about fragilities to their SESs preventing them from adapting their collective actions to changing environmental conditions. A prerequisite that is being argued as critical under uncertain scenarios [9].

On the contrary, G5, despite the lack of conflict resolution mechanisms, can also cope with the effect of uncertainties by capitalizing on their higher adaptive capacity. We find potential explanations for this adaptive capacity on the group members' socio-demographic characteristics. A key element seems to be their age. People in Northwestern Argentina traditionally have great respect for elders; hence, the absence of elder subjects in this group might have fostered younger subjects' participation and the possibility to voice their proposals. However, age seems to be very specific to the kind of adaptation strategies developed by the communities, as shown in Mugi-Ngenga et al. [66]. As the subjects from G5 live and work in the same space, a higher level of trust has probably developed over time, which had a positive effect on investments. These results are in line with previous work (p. 74, [49]; [64,67]). The existent CPRs governance's experience, before we conducted the experiment, might have also played a role. Members of G5 belong to a communitarian cooperative. This potential explanation finds grounds on Pfaff et al.'s [68] results where a subsample of subjects that belonged to a cooperative reported lower levels of extraction from the upstream position during resource scarcity compared to the rest of the sample. It also finds grounds on Farley et al. [15], who indicate that adaptation strategies development is time demanding. Here, the previous experience with CPR governance might have compensated for the time required to develop such strategies. Millen et al. [32] also argue that incorporating community knowledge, in this case, obtained in the previous experience with CPRs, can accelerate adaptation strategies.

We have shown that groups lacking conflict resolution mechanisms (amongst other Design Principles) can also overcome external disturbances over time, challenging the theoretical predictions. This finding is in line with Gari et al. [39], suggesting that forecasting SES endurance based on the DPs assessment might lead to wrong conclusions. 
The results also hint that the flexibility that the 'new normal' requires to adapt to the changing environmental conditions varies not only within sectors [15] but also within the same sector.

Finally, in a reflection of the criticism against the DPs and especially DP6, our study rather justifies Ostrom's distancing from the rigid deterministic nature of DPs as "blueprints" and instead highlights their value as diagnostic tools. We have shown that by utilizing the DPs to investigate issues related to the problem at hand, we were able to go beyond a simple checking of variables, but instead, we identify factors that further highlight the complexity of SES and human behavior. In this frame-and as a concluding sentence-we would like to refer to Ostrom's words calling for "attention to perverse and extensive uses of policy panaceas in misguided efforts to make social-ecological systems (SESs), also called human-environment systems, sustainable over time" (p. 15181, [43]).

\section{Conclusions}

We deployed a multimethod approach that included a framed-field experiment, surveys, interviews, and non-participant observation in Northwest Argentina. Through this methodological design, we could assess our guiding hypothesis: social-ecological systems (SESs) with conflict resolution mechanisms (Ostrom's design principle six-DP6) manage their common-pool resources (CPR) better when exposed to environmental variations.

Our results show that, indeed, groups with a higher 'institutional robustness' and developed conflict resolution (DP6) mechanisms performed well, even under environmental variability. However, groups with weaker 'institutional robustness' also performed well. We explored potential explanatory variables for these unexpected results and found that previous experience in CPR governance as well as certain socio-demographic variables may have influenced the results.

These results do not imply that other group attributes can compensate for the existence (or lack thereof) of conflict-resolution mechanisms. However, our study strongly hints that despite the limitations and the lack of generalization of our results, the specific characteristics exhibited in certain groups illustrate a higher potential to follow mitigation strategies. In a similar line, other unique group characteristics might indicate a community more suited for adaptation strategies.

Our framed-field experiment setting does not allow further investigation on this topic. For example, what would happen if subjects were facing a strict adaptation problem or a mitigation problem? Thus, we urge future studies to explore these potential pathways in the behavior of resource users, as uncertainties related to climate change will escalate. Such direction of future research may have important policy implications as our findings, once again, strongly hint that transplanting institutions that have been successful elsewhere (even in nearby local communities) without understanding why they have succeeded, might disturb a system rather than fortify it. Instead, identifying the particular characteristics of rural communities and building upon their strengths might enhance their resilience and 'institutional robustness'. Future research should also analyze if the adaptation and mitigation combination argued by Adler [9] are also suitable for this particular type of SESs.

Author Contributions: Conceptualization, A.A.D. and D.Z.; Formal analysis, A.A.D. and D.Z.; Funding acquisition, A.A.D. and D.Z.; Investigation, A.A.D. and D.Z.; Methodology, A.A.D.; Resources, A.A.D. and D.Z.; Visualization, A.A.D.; Writing-original draft, A.A.D.; Writing-review \& editing, A.A.D. and D.Z. All authors have read and agreed to the published version of the manuscript.

Funding: This research fieldwork in Argentina was possible thanks to the external funding of the Fiat Panis Foundation. This research communication actions were possible thanks to the support of Fonds de la Recherche Scientifique-FNRS, Université libre de Bruxelles and HTW Berlin-Hochschule für Technik und Wirtschaft Berlin.

Acknowledgments: We would like to thank the Instituto Nacional de Tecnología Agropecuaria (INTA) for their support as gatekeepers during the fieldwork and all the farmers and key informants that actively participated during the fieldwork. The authors would also like to thank the accurate and valuable feedback from Wurzel, Hudon, and Dedeurwaerdere, as well as Janssen for their generosity during the project design phase. The authors would also like to thank the three blind reviewers for their critical perspective that enhanced this paper's quality, as well as the MDPI Academic Editor and team for their support and guidance throughout the publication process. 
Conflicts of Interest: The authors declare no conflict of interest. The funders had no role in the design of the study; in the collection, analyses, or interpretation of data; in the writing of the manuscript, or in the decision to publish the results.

$\begin{array}{ll}\text { Abbreviations } \\ \text { CPR } & \text { Common Pool Resource } \\ \text { DP } & \text { Design Principle } \\ \text { NE } & \text { Social Optimal } \\ \text { SO } & \text { Nash Equilibrium } \\ \text { G } & \text { Group } \\ \text { R } & \text { Round }\end{array}$

\section{References}

1. Zikos, D. Revisiting the Role of Institutions in Transformative Contexts: Institutional Change and Conflicts. Sustainability 2020, 12, 9036. [CrossRef]

2. Paavola, J. Institutions and environmental governance: A reconceptualization. Ecol. Econ. 2007, 63, 93-103. [CrossRef]

3. Adano, W.R.; Dietz, T.; Witsenburg, K.; Zaal, F. Climate Change, Violent Conflict And Local Institutions in Kenya'S Drylands. J. Peace Res. 2012, 49, 65-80. [CrossRef]

4. Humphreys, M. Natural Resources, Conflict, and Conflict Resolution: Uncovering the Mechanisms. J. Conflict Resolut. 2005, 49, 508-537. [CrossRef]

5. Ratner, B.D.; Meinzen-Dick, R.; May, C.; Haglund, E. Resource Conflict, Collective Action, and Resilience: An Analytical Framework. Int. J. Commons 2013, 7, 183-208. [CrossRef]

6. Parry, M. Climate Change and World Agriculture (EBook); Routledge: London, UK, 2019. [CrossRef]

7. Miller, K.A.; Rhodes, S.L.; MacDonnell, L.J. Water Allocation in a Changing Climate: Institutions and Adaptation. Clim. Chang. 1997, 35, 157-177. [CrossRef]

8. Arunanondchai, P.; Fei, C.; Fisher, A.; McCarl, B.A.; Wang, W.; Yang, Y. How Does Climate Change Affect Agriculture? In The Routledge Handbook of Agricultural Economics, 1st ed.; Cramer, G.L., Paudel, K.P., Schmitz, A., Eds.; Routledge: London, UK, 2018. [CrossRef]

9. Adler, J.H. Water Marketing as an Adaptive Response to the Threat of Climate Change. Hamline Law Rev. 2008, 31, 729-754.

10. Mirumachi, N. Transboundary Water Politics in the Developing World, 1st ed.; Routledge: London, UK, 2015. [CrossRef]

11. Mostert, E. Conflict and Co-Operation in International Freshwater Management: A Global Review. Int. J. River Basin Manag. 2003, 1, 267-278. [CrossRef]

12. van der Molen, I.; Hildering, A. Water: Cause for Conflict or Co-Operation? ISYP J. Sci. World Aff. 2005, 1, 133-143.

13. Varisco, A.E. A Study on the Inter-Relation between Armed Conflict and Natural Resources and Its Implications for Conflict Resolution and Peacebuilding. J. Peace Confl. Dev. 2010, 15, 38-58.

14. Wolf, A.T. Shared Waters: Conflict and Cooperation. Annu. Rev. Environ. Resour. 2007, 32, $241-269$. [CrossRef]

15. Farley, K.A.; Tague, C.; Grant, G.E. Vulnerability of Water Supply from the Oregon Cascades to Changing Climate: Linking Science To Users And Policy. Glob. Environ. Chang. 2011, 21, 110-122. [CrossRef]

16. Barros, V.R.; Boninsegna, J.A.; Camilloni, I.A.; Chidiak, M.; Magrín, G.O.; Rusticucci, M. Climate Change in Argentina: Trends, Projections, Impacts and Adaptation. Wiley Interdiscip. Rev. Clim. Chang. 2015, 6, 151-169. [CrossRef]

17. Zaninelli, P.G.; Menéndez, C.G.; Falco, M.; López-Franca, N.; Carril, A.F. Future hydroclimatological changes in South America based on an ensemble of regional climate models. Clim. Dyn. 2018, 52, 819-830. [CrossRef]

18. Ostrom, E. Understanding Institutional Diversity; Princeton University Press: Princeton, NJ, USA, 2005; Volume 132. [CrossRef] 
19. Meinzen-Dick, R.S.; Di Gregorio, M. (Eds.) Collective Action and Property Rights for Sustainable Development. In International Food Policy Research Institute; 2004; pp. 1-36. Available online: https: //www.ifpri.org/publication/collective-action-and-property-rights-sustainable-development-1 (accessed on 11 May 2020).

20. Ostrom, E.; Dietz, T.; Dolšak, N.; Stern, P.C.; Stovich, S.; Weber, E.U. The Drama of the Commons; National Academy Press: Washington, DC, USA, 2002. [CrossRef]

21. Cox, M. Social Capital and Peace-Building: Creating and Resolving Conflict with Trust and Social Networks; Routledge: London, UK, 2008. [CrossRef]

22. Dietz, T.; Ostrom, E.; Stern, P.C. The Struggle to Govern the Commons. Science 2003, 302, 1907-1912. [CrossRef]

23. Anderies, J.M.; Janssen, M.A.J.; Ostrom, E. A Framework to Analyze the Robustness of Social-Ecological Systems from an Institutional Perspective. Ecol. Soc. 2004, 9, 1-18. [CrossRef]

24. Ostrom, E. Design Principles of Robust Property Rights Institutions: What Have We Learned? In Property Rights and Land Policies; Igram, G.K., Hong, Y.H., Eds.; Lincoln Institute of Land Policy: Cambridge, MA, USA, 2009; pp. 25-51. Available online: https:/dlc.dlib.indiana.edu/dlc/bitstream/handle/10535/3785/W0819_Ostrom_DLC.pdf?sequence=1\&isAllowed=y (accessed on 12 March 2017).

25. Safarzynska, K. The Impact of Resource Uncertainty and Intergroup Conflict on Harvesting in the Common-Pool Resource Experiment. Environ. Resour. Econ. 2017, 71, 1001-1025. [CrossRef]

26. Aflaki, S. The Effect of environmental uncertainty on the tragedy of the commons. Games Econ. Behav. 2013, 82, 240-253. [CrossRef]

27. Botelho, A.; Dinar, A.; Costa Pinto, L.M.; Rapoport, A. Time and Uncertainty in Resource Dilemmas: Equilibrium Solutions and Experimental Results. Exp. Econ. 2014, 17, 649-672. [CrossRef]

28. Schmitt, P.; Swope, K.; Walker, J. Collective Action with Incomplete Commitment: Experimental Evidence. South. Econ. J. 2000, 66, 829. [CrossRef]

29. Villamayor-Tomas, S. Cooperation in Common Property Regimes under Extreme Drought Conditions: Empirical Evidence from the Use of Pooled Transferable Quotas in Spanish Irrigation Systems. Ecol. Econ. 2014, 107, 482-493. [CrossRef]

30. Mantilla, C. Environmental Uncertainty in Commons Dilemmas: A Survey of Experimental Research. Int. J. Commons 2018, 12, 300-329. [CrossRef]

31. Anderies, J.M.; Janssen, M.A. The Fragility of Robust Social-Ecological Systems. Glob. Environ. Chang. 2011, 21, 1153-1156. [CrossRef]

32. McMillen, H.; Ticktin, T.; Friedlander, A.M.; Jupiter, S.; Thaman, R.; Campbell, J.; Veitayaki, J.; Giambelluca, T.W.; Nihmei, S.; Rupeni, E.; et al. Small islands, valuable insights: Systems of customary resource use and resilience to climate change in the Pacific. Ecol. Soc. 2014, 19. [CrossRef]

33. Shepsle, K.A. Studying Institutions: Some Lessons from the Rational Choice Approach. J. Theor. Politics 1989, 1, 131-147. [CrossRef]

34. Ostrom, E. Design Principles Of Robust Property Rights Institutions: What Have We Learned? In Elinor Ostrom and the Bloomington School of Political Economy. Resource Governance; Igram, G.K., Hong, Y.H., Eds.; Lincoln Institute of Land Policy: Cambridge, MA, USA, 2015; pp. 215-248. Available online: https://rowman.com/ISBN/9780739191088/Elinor-Ostrom-and-the-Bloomington-School-of-PoliticalEconomy-Resource-Governance-Volume-2 (accessed on 17 December 2020). [CrossRef]

35. Carlson, J.M.; Doyle, J. Complexity and Robustness. Proc. Natl. Acad. Sci. USA 2002, 99 (Suppl. 1), $2538-2545$. [CrossRef]

36. Ostrom, E. Reflection on the Commons. In Governing the Commons; Indiana University: Bloomington, IN, USA, 1990; pp. 1-28.

37. North, D.C. Institutions, Institutional Change and Economic Performance. Institutions, Institutional Change and Economic Performance; Cambridge University Press: Cambridge, MA, USA, 1990. [CrossRef]

38. Cox, M.; Arnold, G.; Tomás, S.V. A Review of Design Principles for Community-Based Natural Resource Management. Ecol. Soc. 2010, 15, 1-38. [CrossRef]

39. Gari, S.R.; Newton, A.; Icely, J.D.; Delgado-Serrano, M.M. An Analysis of the Global Applicability of Ostrom's Design Principles to Diagnose the Functionality of Common-Pool Resource Institutions. Sustainability 2017, 9, 1287. [CrossRef] 
40. Harkes, I.H.T. Fisheries Co-Management, the Role of Local Institutions and Decentralisation in Southeast Asia. With Specific Reference to Marine Sasi in Central Maluku, Indonesia. Universiteit Leiden. 2006. Available online: https://agris.fao.org/agris-search/search.do?recordID=AV20120127450orhttps: //1library.net/document/y4xxorkz-fisheries-management-institutions-decentralisation-southeast-specificreference-indonesia.html (accessed on 30 October 2020).

41. Young, O.R. The Institutional Dimensions of Global Environmental Change. Fit, Interplay, and Scale; MIT Press: Cambridge, MA, USA, 2002.

42. Agrawal, A. Common Resources and Institutional Sustainability. In The Drama of the Commons; Ostrom, E., Dietz, T., Dolšak, N., Stern, P.C., Stovich, S., Weber, U.E., Eds.; The National Academies Press: Washington, DC, USA, 2002; pp. 41-85. [CrossRef]

43. Ostrom, E. A Diagnostic Approach for Going beyond Panaceas. Proc. Natl. Acad. Sci. USA 2007, 104, 15181-15187. [CrossRef]

44. Ostrom, E. A General Framework for Analyzing Sustainability of Social-Ecological Systems. Science 2009, 325, 419-422. [CrossRef]

45. Jat, M.L.; Dagar, J.C.; Sapkota, T.B.; Yadvinder-Singh; Govaerts, B.; Ridaura, S.L.; Saharawat, Y.S.; Sharma, R.K.; Tetarwal, J.P.; Jat, R.K.; et al. Climate Change and Agriculture: Adaptation Strategies and Mitigation Opportunities for Food Security in South Asia and Latin America. In Advances in Agronomy; Sparks, D.L., Ed.; Elsevier Inc.: Cambridge, MA, USA, 2016; Volume 137, pp. 127-235. [CrossRef]

46. Anderies, J.M.; Janssen, M.A.; Lee, A.; Wasserman, H. Environmental Variability and Collective Action: Experimental Insights from an Irrigation Game. Ecol. Econ. 2013. [CrossRef]

47. Dipierri, A.; Alicia, N.D. Uncertainty: Cooperation or Competition in Common Pool Resource Management? Evidence from a Frame Field Water Experiment. Unpublished Manuscript, last modified October 25 Microsoft Word file.

48. Baerlein, T.; Kasymov, U.; Zikos, D. Self-Governance And Sustainable Common Pool Resource Management In Kyrgyzstan. Sustainability 2015, 7, 496-521. [CrossRef]

49. Janssen, M.A.; Bousquet, F.; Cardenas, J.C.; Castillo, D.; Worrapimphong, K. Field Experiments on Irrigation Dilemmas. Agric. Syst. 2012, 109, 65-75. [CrossRef]

50. Pham, L.T.; Otto, I.M.; Zikos, D. Self-Governance and the Effects of Rules in Irrigation Systems: Evidence from Laboratory and Framed Field Experiments in China, India and Vietnam. Water Econ. Policy 2019, 5, 1850009. [CrossRef]

51. Rossner, R.; Zikos, D. The Role of Homogeneity and Heterogeneity Among Resource Users on Water Governance: Lessons Learnt from an Economic Field Experiment on Irrigation in Uzbekistan. Water Econ. Policy 2018, 4. [CrossRef]

52. Rusticucci, M.; Kyselý, J.; Almeira, G.; Lhotka, O. Long-Term Variability of Heat Waves in Argentina and Recurrence Probability of the Severe 2008 Heat Wave in Buenos Aires. Theor. Appl. Clim. 2015, 124, 679-689. [CrossRef]

53. Intercambio Comercial Argentino. Available online: https://www.indec.gob.ar/indec/web/Nivel4-Tema-3-240 (accessed on 29 September 2020).

54. Cabré, M.F.; Solman, S.; Núñez, M. Regional Climate Change Scenarios Over Southern South America for Future Climate (2080-2099) Using The MM5 Model. Mean, Interannual Variability and Uncertainties. Atmósfera 2016, 29, 35-60. [CrossRef]

55. FAO. AQUASTAT Website. 2015. Available online: http://www.fao.org/nr/water/aquastat/countries_regions/ arg/printesp1.stm (accessed on 15 May 2020).

56. Wyatt, A.; Moreda, F.; Brantly, G.; Miralles-Wihelm, F.; Castillo, R.M. Caso de Estudio de Hydro-BID: Un Modelo Del Recurso Hídrico de La Cuenca Del Río Grande En Argentina. 2014. Available online: https://publications.iadb.org/es/caso-de-estudio-de-hydro-bid-no-1-modelo-de-gestion-del-recursohidrico-en-la-cuenca-del-rio-grande (accessed on 30 August 2016).

57. FAO. Estudio: 'Diagnostico de Las Áreas de Riego de La Provincia De Jujuy'. Convenio UTF - PROSAP. Proyecto de Desarrollo Institutional Para La Inversión. 2014. Available online: http://produccion.jujuy.gob.ar/wp-content/ uploads/sites/18/2016/09/ANEXOII-AGROPECUARIO-PROVINCIAL.pdf (accessed on 13 January 2017). 
58. Anderies, J.M.; Janssen, M.A. Social Dilemmas in the Laboratory in Sustaining the Commons. In Sustaining the Commons; Center for Behaviour, Institutions and the Environment: Tempe, Arizona, 2016; pp. 81-90. Available online: https://www.sciencedirect.com/science/article/pii/S0272696304000075? casa_token=hSkqtwX4jxkAAAAA:LVQeC904nrhv6jkBX7tGNqkI6PdsucubO4LEgK8qpHfhJGgKzaKLir5Ompxxo1B7w8DaMv26w (accessed on 6 June 2020).

59. Ketokivi, M.A.; Schroeder, R.G. Perceptual Measures of Performance: Fact or Fiction? J. Oper. Manag. 2004, 22, 247-264. [CrossRef]

60. Huntjens, P.; Lebel, L.; Pahl-Wostl, C.; Camkin, J.; Schulze, R.; Kranz, N. Institutional Design Propositions for the Governance of Adaptation to Climate Change in the Water Sector. Glob. Environ. Chang. 2012, 22, 67-81. [CrossRef]

61. Cárdenas, J.-C.; Rodríguez, L.A.; Johnson, N. Collective Action: Addressing Vertical Asymmetries in Watershed Management. SSRN Electron. J. 2015, 7. [CrossRef]

62. Ibele, B.; Sandri, S.; Zikos, D. Endogenous Versus Exogenous Rules in Water Management: An Experimental Cross-Country Comparison. Mediterr. Politics 2016, 22, 504-536. [CrossRef]

63. Otto, I.M.; Wechsung, F. The Effects of Rules and Communication in a Behavioral Irrigation Experiment with Power Asymmetries Carried out in North China. Ecol. Econ. 2014, 99, 10-20. [CrossRef]

64. Kolinjivadi, V.; Charré, S.; Adamowski, J.; Kosoy, N. Economic Experiments for Collective Action in the Kyrgyz Republic: Lessons for Payments for Ecosystem Services (PES). Ecol. Econ. 2019, 156, 489-498. [CrossRef]

65. Singleton, E.B. What's Missing from Ostrom? Combining Design Principles with the Theory of Sociocultural Viability. Environ. Politics 2017, 26, 994-1014. [CrossRef]

66. Mugi-Ngenga, E.W.; Mucheru-Muna, M.W.; Mugwe, J.N.; Ngetich, F.K.; Mairura, F.S.; Mugendi, D.N. Household's Socio-Economic Factors Influencing the Level of Adaptation to Climate Variability in the Dry Zones of Eastern Kenya. J. Rural. Stud. 2016, 43, 49-60. [CrossRef]

67. Kasymov, U.; Zikos, D. Understanding Human Actions and Institutional Change: What Are the Impacts of Power Asymmetries on Efficiency In Pasture Use? Resources 2017, 6, 71. [CrossRef]

68. Pfaff, A.; Vélez, M.; Ramos, P.A.; Molina, A. Framed Field Experiment on Resource Scarcity \& Extraction: Path-Dependent Generosity within Sequential Water Appropriation. Ecol. Econ. 2015, 120, 416-429. [CrossRef]

Publisher's Note: MDPI stays neutral with regard to jurisdictional claims in published maps and institutional affiliations.

(C) 2020 by the authors. Licensee MDPI, Basel, Switzerland. This article is an open access article distributed under the terms and conditions of the Creative Commons Attribution (CC BY) license (http://creativecommons.org/licenses/by/4.0/). 